\title{
Changes of Peripheral Lymphocyte Populations in Patients with Advanced/Recurrent Ovarian Cancer Undergoing Splenectomy During Cytoreductive Surgery
}

\section{Wei Chen ( $\nabla$ chenwei@mh-hospital.sh.cn )}

Minhang Hospital, Fudan University; The Central Hospital of Minhang District https://orcid.org/00000002-8159-5514

\section{Shuang Ye}

Fudan University Shanghai Cancer Center

\section{Yutuan Wu}

Fudan University Shanghai Cancer Center

\section{Xuan Pei}

Fudan University Shanghai Cancer Center

\section{Libing Xiang}

Fudan University Shanghai Cancer Center

\section{Bo Ping}

Fudan University Shanghai Cancer Center

\section{Boer Shan}

Fudan University Shanghai Cancer Center

\section{Huijuan Yang}

Fudan University Shanghai Cancer Center

\section{Research}

Keywords: Ovarian Neoplasms, Lymphocyte, Subpopulation, Flow cytometry, Splenectomy, Cytoreductive surgery

Posted Date: September 15th, 2020

DOI: https://doi.org/10.21203/rs.3.rs-74741/v1

License: (c) (i) This work is licensed under a Creative Commons Attribution 4.0 International License. Read Full License 


\section{Abstract}

Background: To investigate the change of peripheral lymphocyte subsets after splenectomy during cytoreductive surgery for advanced or recurrent ovarian cancers

Methods: We enrolled 83 patients with advanced or recurrent ovarian cancer who underwent cytoreductive surgery. Twenty patients who also underwent splenectomy were assigned to the splenectomy cohort and the rest to the non-splenectomy cohort. Flow cytometry was used to measure the peripheral lymphocyte subsets consisting of T cells, regulatory T cells, natural killer cells, B cells, and activation antigens before and after surgery.

Results: There wasn't any difference in the number and distribution of peripheral lymphocyte subsets between the two cohorts before surgery. We observed elevated levels of $T$ cells $\left(C D 3^{+}, \mathrm{CD}^{+} \mathrm{CD}^{+}\right)$in the splenectomy cohort compared to those in the non-splenectomy cohort after surgery, which achieved statistical significance. $\mathrm{CD} 8^{+} \mathrm{CD} 28^{+} \mathrm{T}$ cells had a significant decreasing tendency $(P=0.011)$ while $\mathrm{CD}^{+} / \mathrm{HLA}^{-D R^{+}} \mathrm{T}$ cells were the opposite $(P=0.001)$ in the splenectomy cohort. The proportion of Tregs

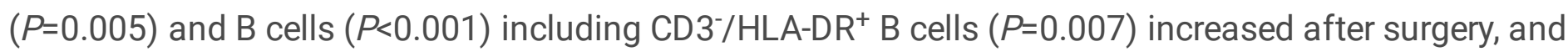
the absolute number of T cells and NK cells decreased to different extents $(P<0.001)$ in the nonsplenectomy cohort. The post-operative percentage of $C D 8^{+} C D 28^{+} T$ cells was less than the pre-operative one $(P=0.022)$, which was similar to the splenectomy cohort.

Conclusions: The changes in peripheral lymphocyte populations were different between patients with and without splenectomy during cytoreductive surgery for ovarian cancers. T cells were increased and activated in splenectomy cohort, whereas, B cells were increased and activated in non-splenectomy.

\section{Background}

Ovarian cancer is the most lethal gynecologic malignancy ${ }^{[1]}$. In China, more than 50,000 new cases and nearly half of the deaths have occurred in 2016, representing the second-highest cause of gynecologic cancer-related death ${ }^{[2]}$. It is well accepted that optimal cytoreduction improves survival in ovarian cancer patients ${ }^{[3,4]}$. In some circumstances, removal of the spleen as part of upper abdominal surgery is required to achieve complete resection ${ }^{[5,6]}$.

As the spleen is one of the most important peripheral immune organs, splenectomy has been suggested to have an impact on immunological function ${ }^{[7]}$. Some studies found that people with splenectomy have a higher risk of developing overall cancer, as well as certain site-specific cancers ${ }^{[8,9]}$. However, the spleen's anti-tumor function is bidirectional, which means that it has a positive anti-tumor role in the early stage of tumor formation, and also a negative immunological impact on tumor progression ${ }^{[10,11]}$. Peripheral lymphocytes that directly reflect the patients' immune status might be influenced by a variety of factors, including surgery especially splenectomy. It is not clear whether splenectomy has a beneficial 
effect on immune function in advanced or recurrent ovarian cancer patients, beyond the benefit of reducing tumor.

In the present study, we aimed to investigate the effect of cytoreductive surgery with or without splenectomy on the immunological status of advanced and recurrent ovarian cancer patients. We compared the pre- and post-operative circulating lymphocyte distribution, and analyzed the changing trends of the two cohorts.

\section{Materials And Methods \\ Patient and comparison groups}

The study was approved by the ethics committee of Fudan University Shanghai Cancer Center. All patients signed informed content. Patients were included who underwent optimal cytoreductive surgery for advanced or recurrent epithelial ovarian cancer between September 2016 and January 2019. The staging was according to the criteria of the International Federation of Gynecology and Obstetrics (FIGO) staging system (2014) ${ }^{[12]}$. Optimal cytoreductive surgery was defined as residual disease less than (or including) $1 \mathrm{~cm}$ after debulking surgery. Twenty patients received splenectomy during cytoreductive surgery for the tumor involvement of spleen. Other patients were grouped into the non- splenectomy group. Patients were excluded in this study if the FIGO stage was less than IIIC, non-epithelial ovarian cancer, presence of other tumors, presence of active infections or immune disease, or lacking complete data.

Clinicopathological features were retrospectively abstracted from the electronic medical records, including age at first diagnosis in our institution, FIGO stage, histological subtypes, pre-treatment serum CA 125, residual disease, and adjuvant chemotherapy. Recurrent diseases were classified into platinum-sensitive disease if the interval time was $>6$ months from the completion of the last platinum-based chemotherapy to the date of disease recurrence, and platinum-resistance disease if the interval time was $<6$ months.

\section{Blood Sample Collection And Flow Cytometry}

Written informed consent was acquired at admission. Peripheral blood samples were collected in heparinized tubes before treatment and after treatment. The average time interval from blood collection to surgery is three days while post-operative blood samples were also collected before discharge, usually one week after the operation. Blood cells were treated with red blood cell lysis buffer (Beyotime, China) and then labeled with fluorochrome-conjugated monoclonal antibodies and incubated at $4{ }^{\circ} \mathrm{C}$ for $20 \mathrm{~min}$. Detailed procedures of flow cytometry using BD Multitest 6-color TBNK reagent (BD Pharmingen, USA) have been described in a previous publication from our institution ${ }^{[13]}$.

\section{Statistical analysis}


Statistical Package for Social Science (SPSS) (Version 20.0, SPSS, Inc., Chicago, IL, USA) was used to analyze all data, and GraphPad Prism (Version 6.0, GraphPad Software, Inc., La Jolla, CA, USA) was utilized to create the artwork. Mean \pm standard deviation (SD) was applied for continuous variables, while absolute numbers followed by percentage (\%) for categorical data. Binomial data from two groups underwent chi-square analysis, and parametric data had Independent-Samples T-tests to seek any differences of characteristics. Lymphocyte subpopulations, non-normally distributed, are shown as median (quartile range, QR). The difference between the groups was determined using the Mann-Whitney $\mathrm{U}$ test. Changes in lymphocyte subsets in patients undergoing different surgeries were evaluated using the Wilcoxon rank test. All $P$ values reported were two-tailed, and a $P$-value $<0.05$ was regarded as statistically significant.

\section{Results}

\section{Patient characteristics}

During the period, a total of 108 patients received cytoreductive surgeries for advanced or recurrent ovarian cancer. Of them, 25 patients were excluded due to incomplete data. Among the rest 83 patients, 20 patients were grouped into the splenectomy cohort (splenectomy during cytoreductive surgery) due to splenic metastasis, and 63 patients were grouped into the non-splenectomy cohort (cytoreductive surgery without splenectomy). At the time of analysis, 16 patients in the splenectomy cohort and 40 patients in the non-splenectomy cohort were available for platinum response assessment. The study participant flow diagram is shown in Fig. 1.

Table 1 shows the demographic and clinicopathological characteristics of the 83 patients. Primary diseases accounted for $70 \%$ and $67.5 \%$ of the cases in the splenectomy group and non-splenectomy group. The age of the patients at the time of diagnosis and the level of CA125 before treatment was not statistically different between the two groups. Most of the patients have high-grade serous carcinomas (90\% and $87.5 \%$ ). Two patients in the splenectomy group received neoadjuvant chemotherapy before surgery, but no significant difference was noted $(P=0.056)$. All patients received optimal debulking with residual disease smaller than $1 \mathrm{~cm}$, while more than $60 \%$ of the cases achieved complete resection $(65 \%$ in the splenectomy group vs. $63.5 \%$ in non-splenectomy group, respectively). Clearly shown in Fig. 1, 56 patients were available for platinum response assessment. Of them, platinum-resistant recurrence accounted for $37.5 \%$ in the splenectomy group and $15.0 \%$ in the non- splenectomy group, respectively, which was not statistically significant. 
Table 1

Demographic and clinicopathological information.

\begin{tabular}{|c|c|c|c|}
\hline Variables & $\begin{array}{l}\text { Splenectomy } \\
(n=20)\end{array}$ & $\begin{array}{l}\text { Non-splenectomy } \\
(n=63)\end{array}$ & $P$-value \\
\hline Age (years), mean (SD, 95\% Cl) & $58(9.7,53-62)$ & $54(8.8,52-56)$ & $0.114^{*}$ \\
\hline Neoadjuvant chemotherapy (\%) & $2(10 \%)$ & 0 & $0.056^{\#}$ \\
\hline \multicolumn{4}{|l|}{ Histology } \\
\hline High-grade serous carcinoma & $18(90.0 \%)$ & $55(87.3 \%)$ & \multirow[t]{5}{*}{$0.246^{\#}$} \\
\hline Clear cell carcinoma & 0 & $5(7.9 \%)$ & \\
\hline Endometrioid & $1(5.0 \%)$ & $1(1.6 \%)$ & \\
\hline Carcinosarcoma & $1(5.0 \%)$ & 0 & \\
\hline Low-grade serous carcinoma & 0 & $2(3.2 \%)$ & \\
\hline Pre-treatment CA125 (U/mL), media (range) & $718.9(8.9-5000)^{a}$ & $539.0(8.3-5000)$ & $0.446^{* *}$ \\
\hline \multicolumn{4}{|l|}{ FIGO stage (\%) } \\
\hline IIIC & $11(55.0 \%)$ & $33(52.4 \%)$ & \multirow[t]{3}{*}{$0.838^{\#}$} \\
\hline IV & $3(15.0 \%)$ & $14(22.2 \%)$ & \\
\hline Recurrence & $6(30.0 \%)$ & $16(25.4 \%)$ & \\
\hline \multicolumn{4}{|l|}{ Residual disease (\%) } \\
\hline 0 & $13(65.0 \%)$ & $40(63.5 \%)$ & \multirow[t]{2}{*}{$0.903^{\#}$} \\
\hline$\leq 1 \mathrm{~cm}$ (optimal) & $7(35.0 \%)$ & $23(36.5 \%)$ & \\
\hline \multicolumn{4}{|l|}{ Platinum response (\%) ${ }^{b}$} \\
\hline Sensitive & $10(50.0 \%)$ & $34(54.0 \%)$ & \multirow[t]{2}{*}{$0.093^{\#}$} \\
\hline Resistant & $6(30.0 \%)$ & $6(9.5 \%)$ & \\
\hline
\end{tabular}


a The upper limit of CA 125 detection is 5000.

${ }^{b}$ Sixteen patients in splenectomy group and 40 patients in control group were available for platinum response assessment.

*Independent-Sample T test

${ }^{* *}$ Mann-Whitney U test

\# chi-square or Fisher's exact test.

$P$-value $<0.05$ was deemed statistically significant.

Abbreviations:

FIGO = The International Federation of Gynecology and Obstetrics;

CA125 = Cancer Antigen 125.

\section{Lymphocyte subsets in peripheral blood: Before surgery vs. After surgery}

By flow cytometry, the circulating lymphocyte subpopulations were measured, including $\mathrm{T}$ cells $\left(\mathrm{CD}^{+}\right.$, $\mathrm{CD}^{+}{ }^{+} \mathrm{CD} 4^{+}, \mathrm{CD} 3^{+} \mathrm{CD} 8^{+}$and $\mathrm{CD} 8^{+} \mathrm{CD} 28^{+}$), regulatory $\mathrm{T}$ cells (Tregs, $\mathrm{CD} 4^{+} \mathrm{CD} 25^{+} \mathrm{CD} 127^{-}$), activated $\mathrm{T}$ cells $\left(\mathrm{CD}^{+} / \mathrm{HLA}^{-D R^{+}}\right)$, natural killer cells (NK cells, $\left.\mathrm{CD} 3^{-} \mathrm{CD} 56^{+}\right)$and $\mathrm{B}$ cells $\left(\mathrm{CD} 19^{+}, \mathrm{CD}^{-} / \mathrm{HLA}^{-D R^{+}}\right)$. Preoperative and post-operative data of the two cohorts were presented in Table 2. Before surgery, the percentage and the absolute number of peripheral lymphocyte subpopulations were quite comparable between the splenectomy cohort and the non- splenectomy cohort. After surgery, the difference between the two groups was demonstrated in Fig. 2. The median absolute number of $\mathrm{CD}^{+} \mathrm{T}$ cells was significantly higher in the splenectomy cohort than that in the non- splenectomy cohort (1079 vs. 821, $P=$ 0.013). This was mainly due to the difference in the absolute number of $C D 3^{+} \mathrm{CD} 8^{+} \mathrm{T}$ cells (splenectomy vs. non- splenectomy: 411 vs. $313, P=0.012$ ). Therefore, the $C D 4 / C D 8$ ratio of the splenectomy group was lower compared to the non-splenectomy group (1.2 vs. $1.7, P=0.048)$. 
Table 2

Distributions of peripheral lymphocyte subpopulations in two groups before and after surgery.

\begin{tabular}{|c|c|c|c|c|c|c|c|c|}
\hline \multirow{2}{*}{$\begin{array}{l}\text { Peripheral lymphocyte } \\
\text { subsets }\end{array}$} & \multicolumn{3}{|c|}{ Splenectomy group } & \multicolumn{3}{|c|}{ Non-splenectomy group } & \multirow[t]{2}{*}{$P_{1}$} & \multirow[t]{2}{*}{$P_{2}$} \\
\hline & pre & post & $P_{3}$ & pre & post & $P_{4}$ & & \\
\hline \multicolumn{9}{|l|}{ Percentage (\%) } \\
\hline T cells $\left(\mathrm{CD}^{+}\right)$ & $\begin{array}{l}67.8 \\
(17.3)\end{array}$ & $\begin{array}{l}68.9 \\
(16.0)\end{array}$ & 0.241 & $\begin{array}{l}67.6 \\
(14.48)\end{array}$ & $\begin{array}{l}69.1 \\
(12.9)\end{array}$ & 0.276 & 0.680 & 0.431 \\
\hline $\mathrm{CD}^{+} \mathrm{CD}^{+}$ & $\begin{array}{l}30.1 \\
(12.2)\end{array}$ & $\begin{array}{l}26.2 \\
(16.5)\end{array}$ & 0.210 & $\begin{array}{l}25.2 \\
(12.50)\end{array}$ & $\begin{array}{l}27.1 \\
(14.5)\end{array}$ & 0.056 & 0.109 & 0.289 \\
\hline $\mathrm{CD}^{+} \mathrm{CD} 4^{+}$ & $\begin{array}{l}37.7 \\
(7.1)\end{array}$ & $\begin{array}{l}35.5 \\
(9.2)\end{array}$ & 0.768 & $\begin{array}{l}38.2 \\
(12.8)\end{array}$ & $\begin{array}{l}39.7 \\
(12.8)\end{array}$ & 0.292 & 0.616 & 0.070 \\
\hline CD4/CD8 & $\begin{array}{l}1.2 \\
(0.8)\end{array}$ & $\begin{array}{l}1.2 \\
(0.8)\end{array}$ & 0.746 & $\begin{array}{l}1.6 \\
(0.9)\end{array}$ & $\begin{array}{l}1.7 \\
(1.3)\end{array}$ & 0.038 & 0.125 & 0.048 \\
\hline $\mathrm{CD}^{+} \mathrm{CD} 28^{+}$ & $\begin{array}{l}8.9 \\
(4.1)\end{array}$ & $\begin{array}{l}7.6 \\
(3.9)\end{array}$ & 0.011 & $\begin{array}{l}6.9 \\
(4.3)\end{array}$ & $\begin{array}{l}6.8 \\
(3.4)\end{array}$ & 0.022 & 0.116 & 0.606 \\
\hline $\begin{array}{l}\text { NK cells } \\
\left(\text { CD3 }^{-} \text {CD16 }\right. \\
\end{array}$ & $\begin{array}{l}16.1 \\
(12.9)\end{array}$ & $\begin{array}{l}11.2 \\
(13.9)\end{array}$ & 0.312 & $\begin{array}{l}15.8 \\
(14.0)\end{array}$ & $\begin{array}{l}13.5 \\
(13.3)\end{array}$ & 0.043 & 0.721 & 0.563 \\
\hline $\mathrm{B}$ cells $\left(\mathrm{CD}^{-}{ }^{-} \mathrm{CD} 19^{+}\right)$ & $\begin{array}{l}10.5 \\
(9.5)\end{array}$ & $\begin{array}{l}11.4 \\
(8.6)\end{array}$ & 0.922 & $\begin{array}{l}11.3 \\
(6.9)\end{array}$ & $\begin{array}{l}13.9 \\
(7.7)\end{array}$ & $<0.001$ & 0.880 & 0.195 \\
\hline $\begin{array}{l}\text { Tregs } \\
\left(\mathrm{CD} 4^{+} \mathrm{CD} 25^{+} \mathrm{CD} 127^{\text {low }}\right)\end{array}$ & $\begin{array}{l}13.2 \\
(3.3)\end{array}$ & $\begin{array}{l}14.6 \\
(4.1)\end{array}$ & 0.344 & $\begin{array}{l}12.8 \\
(4.0)\end{array}$ & $\begin{array}{l}13.2 \\
(4.2)\end{array}$ & 0.005 & 0.477 & 0.461 \\
\hline HLA-DR ${ }^{+}$ & $\begin{array}{l}22.5 \\
(13.6)\end{array}$ & $\begin{array}{l}26.2 \\
(19.1)\end{array}$ & 0.011 & $\begin{array}{l}22.8 \\
(18.2)\end{array}$ & $\begin{array}{l}26.3 \\
(15.8)\end{array}$ & 0.003 & 0.812 & 0.864 \\
\hline $\mathrm{CD}^{+} / \mathrm{HLA}^{-\mathrm{DR}^{+}}$ & $\begin{array}{l}6.3 \\
(17.4)\end{array}$ & $\begin{array}{l}9.3 \\
(19.4)\end{array}$ & 0.001 & $\begin{array}{l}11.3 \\
(13.9)\end{array}$ & $\begin{array}{l}11.3 \\
(14.6)\end{array}$ & 0.198 & 0.563 & 0.969 \\
\hline $\mathrm{CD}^{-} / \mathrm{HLA}^{-\mathrm{DR}^{+}}$ & $\begin{array}{l}10.3 \\
(8.5)\end{array}$ & $\begin{array}{l}13.7 \\
(11.2)\end{array}$ & 0.177 & $\begin{array}{l}11.6 \\
(6.8)\end{array}$ & $\begin{array}{l}13.6 \\
(6.3)\end{array}$ & 0.010 & 0.570 & 0.843 \\
\hline $\mathrm{CD}^{+} / \mathrm{HLA}^{-\mathrm{DR}}{ }^{-}$ & $\begin{array}{l}59.2 \\
(17.3)\end{array}$ & $\begin{array}{l}49.6 \\
(22.6)\end{array}$ & $<0.001$ & $\begin{array}{l}57.4 \\
(17.2)\end{array}$ & $\begin{array}{l}55.9 \\
(18.6)\end{array}$ & 0.002 & 0.669 & 0.093 \\
\hline \multicolumn{9}{|l|}{ Absolute number (cell/ul) } \\
\hline T cells $\left(\mathrm{CD}^{+}\right)$ & $\begin{array}{l}942 \\
(522)\end{array}$ & $\begin{array}{l}1079 \\
(502)\end{array}$ & 0.522 & $\begin{array}{l}1101 \\
(466)\end{array}$ & $\begin{array}{l}821 \\
(543)\end{array}$ & $<001$ & 0.226 & 0.013 \\
\hline $\mathrm{CD}^{+} \mathrm{CD} 8^{+}$ & $\begin{array}{l}406 \\
(290)\end{array}$ & $\begin{array}{l}411 \\
(261)\end{array}$ & 0.709 & $\begin{array}{l}416 \\
(251)\end{array}$ & $\begin{array}{l}313 \\
(237)\end{array}$ & $\begin{array}{l}< \\
0.001\end{array}$ & 0.868 & 0.012 \\
\hline $\mathrm{CD}^{+} \mathrm{CD}^{+}$ & $\begin{array}{l}495 \\
(273)\end{array}$ & $\begin{array}{l}611 \\
(263)\end{array}$ & 0.490 & $\begin{array}{l}594 \\
(416)\end{array}$ & $\begin{array}{l}465 \\
(311)\end{array}$ & $<.001$ & 0.111 & 0.140 \\
\hline
\end{tabular}




\begin{tabular}{|c|c|c|c|c|c|c|c|c|}
\hline \multirow{2}{*}{$\begin{array}{l}\text { Peripheral lymphocyte } \\
\text { subsets }\end{array}$} & \multicolumn{3}{|c|}{ Splenectomy group } & \multicolumn{3}{|c|}{ Non-splenectomy group } & \multirow[t]{2}{*}{$P_{1}$} & \multirow[t]{2}{*}{$P_{2}$} \\
\hline & pre & post & $P_{3}$ & pre & post & $P_{4}$ & & \\
\hline $\begin{array}{l}\text { NK cells } \\
\left(\text { CD3 }^{-} \text {CD16 } 56^{+}\right)\end{array}$ & $\begin{array}{l}201 \\
(47)\end{array}$ & $\begin{array}{l}161 \\
(276)\end{array}$ & 0.595 & $\begin{array}{l}255 \\
(236)\end{array}$ & $\begin{array}{l}162 \\
(173)\end{array}$ & $<.001$ & 0.250 & 0.510 \\
\hline B cells $\left(\mathrm{CD}^{-}{ }^{-} \mathrm{CD} 19^{+}\right)$ & $\begin{array}{l}152 \\
(194)\end{array}$ & $\begin{array}{l}149 \\
(158)\end{array}$ & 0.241 & $\begin{array}{l}164 \\
(133)\end{array}$ & $\begin{array}{l}160 \\
(147)\end{array}$ & 0.380 & 0.572 & 0.570 \\
\hline \multicolumn{9}{|c|}{$\begin{array}{l}\text { a Numbers were presented as median (quartile rang). } \\
\text { b Pre = before surgery; Post = after surgery. } \\
\text { c } P \text { values with statistical significance were denoted. } P_{1}=\text { Splenectomy vs. Control before surgery; } P_{2} \\
=\text { Splenectomy vs. Control after surgery; } P_{3}=\text { Preoperative vs. Postoperative in the splenectomy cohort; } \\
P_{4}=\text { Preoperative vs. Postoperative in the control cohort. }\end{array}$} \\
\hline
\end{tabular}

\section{Change trends before and after surgery: Splenectomy vs. Non- splenectomy group}

As shown in Fig. 3 , in the splenectomy cohort, the median percentage of $\mathrm{CD} 8^{+} \mathrm{CD} 28^{+} \mathrm{T}$ cells levels significantly decreased after the operation (pre-operative vs. post-operative: 8.9 vs. $7.6, P=0.011$ ), while the median percentage of activation antigens significantly increased (HLA-DR ${ }^{+}$, pre-operative vs. postoperative: 22.5 vs. $26.2, P=0.011$ ), which was mainly reflected in the increase of the percentage of activated $\mathrm{CD}^{+} / \mathrm{HLA}-\mathrm{DR}{ }^{+} \mathrm{T}$ cells (preoperative vs. post-operative: 6.3 vs. 9.3, $P=0.001$ ), with the decline of the percentage of $\mathrm{CD}^{+} / \mathrm{HLA}^{-\mathrm{DR}^{-}}$(pre-operative vs. post-operative: 59.2 vs. $49.6, P<0.001$ ). Other variables remained unchanged before and after the operation.

Correspondingly, in addition to the percentage of T cells, almost all other variables changed significantly after debulking in the non-splenectomy cohort. The absolute numbers (presented in Fig. 4) of postoperative T cells $\left(\mathrm{CD}^{+}, \mathrm{CD}^{+} \mathrm{CD} 8^{+}, \mathrm{CD}^{+} \mathrm{CD}^{+}\right)$were lower than preoperative ones $(P<0.001)$. The absolute number and percentage of post-operative NK cells $\left(\mathrm{CD}^{-} \mathrm{CD} 16^{+} 56^{+}\right)$also declined (absolute number: 255 vs. $162, P<0.001$; percentage: 15.8 vs. $13.5, P=0.043)$. There were no significant differences in the absolute number of $\mathrm{B}$ cells $\left(\mathrm{CD} 3^{-} \mathrm{CD} 19^{+}\right)$, but the percentage was higher than that before surgery $(P$ $<0.001)$ which was mainly due to decreased absolute numbers of T cells and NK cells. The post-operative percentage of Tregs $\left(\mathrm{CD} 4^{+} \mathrm{CD} 25^{+} \mathrm{CD} 127^{\mathrm{low}}\right)$ was significantly greater than the pre-operative one $(P=$ 0.005). The post-operative percentage of $\mathrm{CD}^{+} \mathrm{CD} 28^{+} \mathrm{T}$ cells went down $(P=0.022)$ and the activation antigens $\left(\mathrm{HLA}^{-} \mathrm{DR}^{+}\right)$went up $(P=0.003)$.

In terms of absolute numbers of peripheral lymphocyte subpopulations, the changes of B cells were not significant in the two cohorts, while the NK cells decreased, in which the non-splenectomy cohort showed significant changes $(P<0.001)$. The post-operative T cells' value in the splenectomy group went up $(P>$ 0.05), while in the non-splenectomy group went down $(P<0.01)$. In terms of the percentage, elevated 
levels of B cells and Tregs as declining levels of NK cells were found in both groups. These changes in the non-splenectomy group were significant $(P<0.05)$, and more obvious than that of the splenectomy group. CD $8{ }^{+} C D 28^{+} T$ cells levels of both cohorts decreased significantly $(P<0.05)$, but only the CD4/CD8 ratio of non-splenectomy cohort increased $(P=0.038)$. After debulking, the proportion of lymphocytes with activated antigens (HLA-DR ${ }^{+}$) was greater than before in both groups. The changes were reflected in a significant increase in the percentage of activated T cells $\left(\mathrm{CD}^{+} / \mathrm{HLA}^{\left.-\mathrm{DR}^{+}\right)}\right.$in the splenectomy cohort $(P=$ $0.001)$, compared with activated $\mathrm{B}$ cells $\left(\mathrm{CD}^{-} / \mathrm{HLA}^{\left.-\mathrm{DR}^{+}\right)}\right.$in the non-splenectomy cohort $(P=0.007)$.

In summary, the changes of peripheral lymphocyte subpopulations were not completely identical in patients with splenectomy and without splenectomy during debulking surgeries for advanced or recurrent ovarian cancers. $\mathrm{CD}^{+} \mathrm{T}$ cells and $\mathrm{CD} 8^{+} \mathrm{T}$ cells were significantly increased in patients with splenectomy, whereas, decreased in patients without splenectomy. Activation antigen (HLA-DR ${ }^{+}$) was increased in T cells from the patients with splenectomy and in B cells from the patients without splenectomy. In the nonsplenectomy group, NK cells significantly decreased and Tregs significantly increased after surgery, which did not reach statistical significance in the splenectomy group. $C D 8^{+} \mathrm{CD} 28^{+} \mathrm{T}$ cells are decreased in both groups. And B cells were not significantly changed after surgery in both groups.

\section{Discussion}

It has been well accepted that patients with advanced tumors present an immunosuppressive status ${ }^{[14]}$. The spleen, as the most important peripheral immune organ, plays a negative immunologic role in it ${ }^{[7]}$. Surgery is the standard treatment of $\mathrm{OC}$ and may assist in restoring the immune response ${ }^{[15]}$. A report suggested that the anti-tumor effect of the immunologic function of the spleen was restored when the negative factor resulting in immune suppression produced by tumor cells was eliminated by debulking surgery ${ }^{[11]}$. Our results showed that the decrease of postoperative $\mathrm{CD} 8^{+} \mathrm{CD} 28^{+} \mathrm{T}$ cells and NK cells in both groups indicated that the postoperative anti-tumor immunity of ovarian cancer patients was suppressed. Immune functional changes after surgery were less apparent in the ovarian cancer patients with splenectomy compared to those without splenectomy. The changes, such as the decrease in the absolute number of T cells and NK cells, the increase of the proportion of Tregs $\left(C D 4^{+} \mathrm{CD} 25^{+}\right)$and $B$ cells, did not occur in the splenectomy group. Correspondingly, $\mathrm{T}$ cells levels of $\mathrm{CD} 3^{+}$and $\mathrm{CD} 3^{+} \mathrm{CD} 8^{+}$in the nonsplenectomy group were significantly lower than those in the splenectomy group. All these might suggest that the spleen played a part in postoperative immunosuppression in mediating the changes of peripheral blood lymphocytes. So, splenectomy could reduce the immune suppression of ovarian cancer patients caused by surgery.

Increased circulating Tregs have been reported in patients with different kinds of malignant tumors, including ovarian cancer ${ }^{[13,16-18]}$. Studies have considered that Tregs mainly stores in the spleen ${ }^{[19]}$. They might be set free by the spleen into circulation during post-operative immune rearrangement, which could explain why $\mathrm{CD} 4^{+}$Tregs increased in patients with spleen preservation after surgery. $\mathrm{CD} 4^{+}$Tregs, 
one of the major Tregs subtypes reported to date, can inhibit the tumor-specific T cell-mediated immune response and contribute to tumor escape and poor survival ${ }^{[20,21]}$.

The role of $\mathrm{B}$ cells in ovarian cancer is difficult to determine. An experiment in the laboratory indicated that $B$ cells migrated to the site of the tumor and acquire expression of immunosuppressive ligands and/or cytokines that contributed to the inhibition of anti-tumor immune response ${ }^{[22]}$. Another publication showed that B cells infiltrating high-grade serous ovarian cancer omental metastases supported the development of an antitumor response ${ }^{[23]}$. The antitumor effect of $B$ cells in peripheral circulation is rarely studied. In our study, the reason for the increased B cells proportions may be the same as that for Tregs, since the spleen is the largest $B$ cell producing organ. The spleen might play a role in regulating the number of $B$ cells in peripheral blood and keeping stable when the depression of the immune response was evoked owing to the serious attack from surgical trauma. Therefore, the immune benefit is limited, because the increase of B cell proportion is based on the decrease of $T$ and NK cell proportion. The absolute number did not increase.

In the splenectomy group, the changes in immune status were not so obvious as those in the nonsplenectomy group. We noted that the proportion of activated antigens (HLA-DR $\left.{ }^{+}\right)$increased within 1-2 weeks post-operatively. It was taken into account in T cells $\left(\mathrm{CD}^{+} / \mathrm{HLA}^{\left.-D R^{+}\right)}\right.$of splenectomy group and $\mathrm{B}$ cells $\left(\mathrm{CD}^{-} / \mathrm{HLA}^{-D R^{+}}\right)$of the non-splenectomy group. Studies on the role of $\mathrm{HLA}^{-\mathrm{DR}^{+}}$in tumor immunity were rare and remain controversial. Our previous related study identified that an HLA-DR Tregs population in the peripheral blood was significantly increased in cervical cancer patients compared to precancer patients and healthy donors ${ }^{[24]}$. Activated T cells $\left(\mathrm{CD}^{+} / \mathrm{HLA}^{\left.-\mathrm{DR}^{+}\right)}\right.$were found to increase during chemotherapy for non-Hodgkin's lymphoma patients, then reduce after chemotherapy, and the elevated level was associated with recurrence ${ }^{[25]}$. For ovarian cancer patients, the activated $T$ cells have proved to be related to the size of residual tumors ${ }^{[26]}$. Under normal conditions, the majority of $T$ cells are $C D 4^{+} T$ helper (Th) 1 and $C D 8^{+}$T cytotoxic (Tc) 1 cell. Th1/Tc1 immune responses, enhance HLA-DR expression in $T$ cells in the inflamed sites, can lead to an increase in $C D 3^{+} H L A-D R^{+}$extracellular vesicle levels in the circulation ${ }^{[27]}$. Recent progress in cancer immunotherapy has disclosed that Th1/Tc1 responses are suppressed in cancer patients and they are restored by blockade of immune checkpoint receptor PD-1 or PD-L1 ${ }^{[28]}$. In our study, post-operative activated T cell elevation was unique to the splenectomy group. Regardless of whether this phenomenon was caused by post-operative inflammatory stimulation or decreased tumor load, it seemed to provide diverse ideas for postoperative immunotherapy. Kikuchi et.al found that the percentage and absolute number of $\mathrm{CD}^{-} / \mathrm{HLA}^{-\mathrm{DR}^{+}}$(B cells) in peripheral blood of patients with advanced ovarian carcinoma were significantly lower than values from patients with benign ovarian tumor ${ }^{[26]}$. In the present study, we found an increase in $\mathrm{CD}^{-} / \mathrm{HLA}^{-D R^{+}}$cells post-operatively only in the spleen-preserving group. Whether the increased activation of $B$ cells can promote tumor immunity remains to further study.

Thus, the changes of peripheral lymphocyte populations were different between patients with and without splenectomy during cytoreductive surgery for ovarian cancers. T cells were increased and activated in 
splenectomy cohort, whereas, B cells were increased and activated in non-splenectomy. The release of spleen function after surgery does not necessarily reflect to remove the immunosuppression but seems to intensify tumor immune escape within two weeks after surgery. Ovarian cancer debulking combined with splenectomy has a little negative effect on peripheral lymphocyte subpopulation distribution but seemed to be beneficial to the balance of $\mathrm{T}$ cell subsets and improves the antitumor immune function. It is advantageous to the post-operative chemotherapy and immunotherapy as soon as possible after surgery.

The study presents several limitations. Firstly, a one-time snapshot of lymphocyte values could not reflect the kinetics. Prolonged observation might lead to a different conclusion considering the time needed for the immune function reaches a different balance. We intend to collect consecutive blood samples for further study. Secondly, due to short follow-up time, evaluation of platinum resistance was only obtainable in some patients and the survival outcome was not analyzed. We will update the survival information and investigate the possible prognostic implication of lymphocyte variables. Thirdly, we only analyzed the lymphocyte subsets mentioned above, and additional tests were required for other subsets. Lastly, given the limited case number, the result might partly explain the insignificant differences between ovarian cancer patients with and without splenectomy.

\section{Conclusion}

The changes of peripheral lymphocyte populations were different between patients with and without splenectomy during cytoreductive surgery for ovarian cancers. T cells were increased and activated in splenectomy cohort, whereas, B cells were increased and activated in non-splenectomy. Therefore, postoperative adjuvant therapy, including immunotherapy, needs to be customized.

\section{Abbreviations}

Tregs: regulatory T cells; NK: natural killer; FIGO: The International Federation of Gynecology and Obstetrics; CA: cancer antigen.

\section{Declarations}

\section{Funding}

Not applicable

\section{Conflicts of interest}

The authors declare that they have no competing interests.

\section{Ethics approval}

The study was conducted in accordance with the Declaration of Helsinki and its amendments and with Good Clinical Practice guidelines. Ethical approval for this study was obtained from the institutional 
review board at Fudan University Shanghai Cancer Center, Shanghai, China.

\section{Consent to participate}

Informed consent was obtained from all individual participants included in the study.

\section{Consent for publication}

Patients signed informed consent regarding publishing their data.

\section{Availability of data and material}

The datasets generated during and/or analyzed during the current study are available from the corresponding author on reasonable request.

\section{Code availability}

Not applicable

\section{Authors' contributions:}

WC, SY, YW, XP, LX, BP, BS, and HY contributed to the conceptualization and design of the study. WC, SY, $\mathrm{YW}$, and LX collected and analyzed patients' clinicopathological data. XP, BP, and BS performed and analyzed the flow cytometry. WC, SY, BS, and HY were major contributors in writing the manuscript. WC, $S Y, Y W, X P, L X, B P, B S$, and $H Y$ read and approved the final manuscript.

\section{Acknowledgments:}

Not applicable

\section{References}

1. Torre LA, Bray F, Siegel RL, et al. Global cancer statistics, 2012. CA Cancer J Clin. 2015;65:87-108.

2. Chen W, Zheng R, Baade PD, et al. Cancer statistics in China, 2015. CA Cancer J Clin.66:115-132.

3. Eisenhauer EL, Abu-Rustum NR, Sonoda Y, et al. The effect of maximal surgical cytoreduction on sensitivity to platinum-taxane chemotherapy and subsequent survival in patients with advanced ovarian cancer. Gynecol Oncol. 2008;108:276-81.

4. Vergote I, Trope CG, Amant F, et al. Neoadjuvant chemotherapy or primary surgery in stage IIIC or IV ovarian cancer. N Engl J Med. 2010;363:943-53.

5. Sun $\mathrm{H}, \mathrm{Bi}$ X, Cao D, et al. Splenectomy during cytoreductive surgery in epithelial ovarian cancer. Cancer Manag Res. 2018;10:3473-82.

6. Xiang $L$, Tu Y, He T, et al. Distal pancreatectomy with splenectomy for the management of splenic hilum metastasis in cytoreductive surgery of epithelial ovarian cancer. J Gynecol Oncol. 2016;27:e62. 
7. Jordan KR, Kapoor P, Spongberg E, et al. Immunosuppressive myeloid-derived suppressor cells are increased in splenocytes from cancer patients. Cancer Immunol Immunother. 2017;66:503-13.

8. Kristinsson SY, Gridley G, Hoover RN, et al. Long-term risks after splenectomy among 8,149 cancerfree American veterans: a cohort study with up to 27 years follow-up. Haematologica. 2014;99:3928.

9. Sun LM, Chen HJ, Jeng LB, et al. Splenectomy and increased subsequent cancer risk: a nationwide population-based cohort study. Am J Surg. 2015;210:243-51.

10. Levy L, Mishalian I, Bayuch R, et al. Splenectomy inhibits non-small cell lung cancer growth by modulating anti-tumor adaptive and innate immune response. Oncoimmunology. 2015;4:e998469.

11. Pan D, Chen H, Li LQ, et al. Effect of Splenectomy Combined with Resection for Gastric Carcinoma on Patient Prognosis. Med Sci Monit. 2016;22:4205-9.

12. Prat J. Staging classification for cancer of the ovary, fallopian tube, and peritoneum. Int J Gynaecol Obstet. 2014;124:1-5.

13. Xu YF, Lu Y, Cheng H, et al. Abnormal distribution of peripheral lymphocyte subsets induced by PDAC modulates overall survival. Pancreatology. 2014;14:295-301.

14. Vinay DS, Ryan EP, Pawelec G, et al. Immune evasion in cancer: Mechanistic basis and therapeutic strategies. Semin Cancer Biol. 2015;35 Suppl: S185-s198.

15. Wicherek L, Jozwicki W, Windorbska W, et al. Analysis of Treg cell population alterations in the peripheral blood of patients treated surgically for ovarian cancer - a preliminary report. Am J Reprod Immunol. 2011;66:444-50.

16. Ormandy LA, Hillemann T, Wedemeyer $\mathrm{H}$, et al. Increased populations of regulatory $\mathrm{T}$ cells in peripheral blood of patients with hepatocellular carcinoma. Cancer Res. 2005;65:2457-64.

17. Chen $C$, Chen D, Zhang Y, et al. Changes of CD4 + CD25 + FOXP3 + and CD8 + CD28- regulatory T cells in non-small cell lung cancer patients undergoing surgery. Int Immunopharmacol. 2014;18:25561.

18. Wu M, Chen X, Lou J, et al. Changes in regulatory $T$ cells in patients with ovarian cancer undergoing surgery: Preliminary results. Int Immunopharmacol. 2017;47:244-50.

19. Richards DM, Delacher M, Goldfarb Y, et al. Treg Cell Differentiation: From Thymus to Peripheral Tissue. Prog Mol Biol Transl Sci. 2015;136:175-205.

20. Roux S, Apetoh L, Chalmin F, et al. CD4 + CD25 + Tregs control the TRAIL-dependent cytotoxicity of tumor-infiltrating DCs in rodent models of colon cancer. J Clin Invest. 2008;118:3751-61.

21. Liu H, Xu L, Wei JE, et al. Role of CD4 + CD25 + regulatory T cells in melatonin-mediated inhibition of murine gastric cancer cell growth in vivo and in vitro. Anat Rec (Hoboken). 2011;294:781-8.

22. Zhang $Y$, Morgan $R$, Podack ER, et al. B cell regulation of anti-tumor immune response. Immunol Res. 2013;57:115-24.

23. Montfort A, Pearce O, Maniati E, et al. A Strong B-cell Response Is Part of the Immune Landscape in Human High-Grade Serous Ovarian Metastases. Clin Cancer Res. 2017;23:250-62. 
24. Yang H, Ye S, Goswami S, et al. Highly immunosuppressive HLADR(hi) regulatory T cells are associated with unfavorable outcomes in cervical squamous cell carcinoma. Int $\mathrm{J}$ Cancer. 2020;146:1993-2006.

25. Varoczy L, Gergely L, Miltenyi Z, et al. Can CD3+/HLA-DR + activated T cells predict the prognosis of non-Hodgkin's lymphoma patients? Immunol Lett. 2005;97:155-7.

26. Kikuchi Y, Iwano I, Kita T, et al. Changes of lymphocyte subsets in peripheral blood before and after operation of patients with advanced ovarian carcinoma. J Cancer Res Clin Oncol. 1990;116:283-7.

27. Oba R, Isomura M, Igarashi A, et al. Circulating CD3(+)HLA-DR(+) Extracellular Vesicles as a Marker for Th1/Tc1-Type Immune Responses. J Immunol Res. 2019;2019:6720819.

28. Li J, Jie H-B, Lei Y, et al. PD-1/SHP-2 inhibits Tc1/Th1 phenotypic responses and the activation of T cells in the tumor microenvironment. Cancer research. 2015;75:508-18.

\section{Figures}

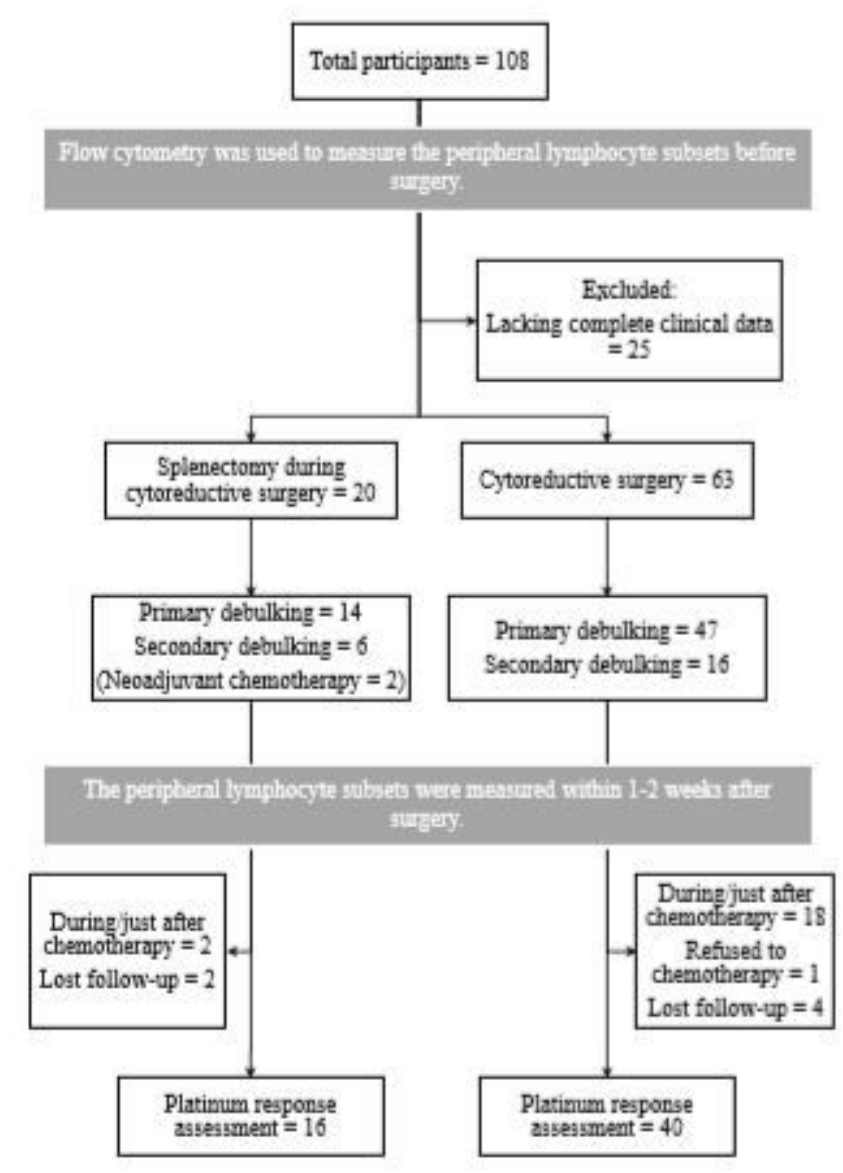

\section{Figure 1}

Schematic flowchart of the patients contained in the present study. 

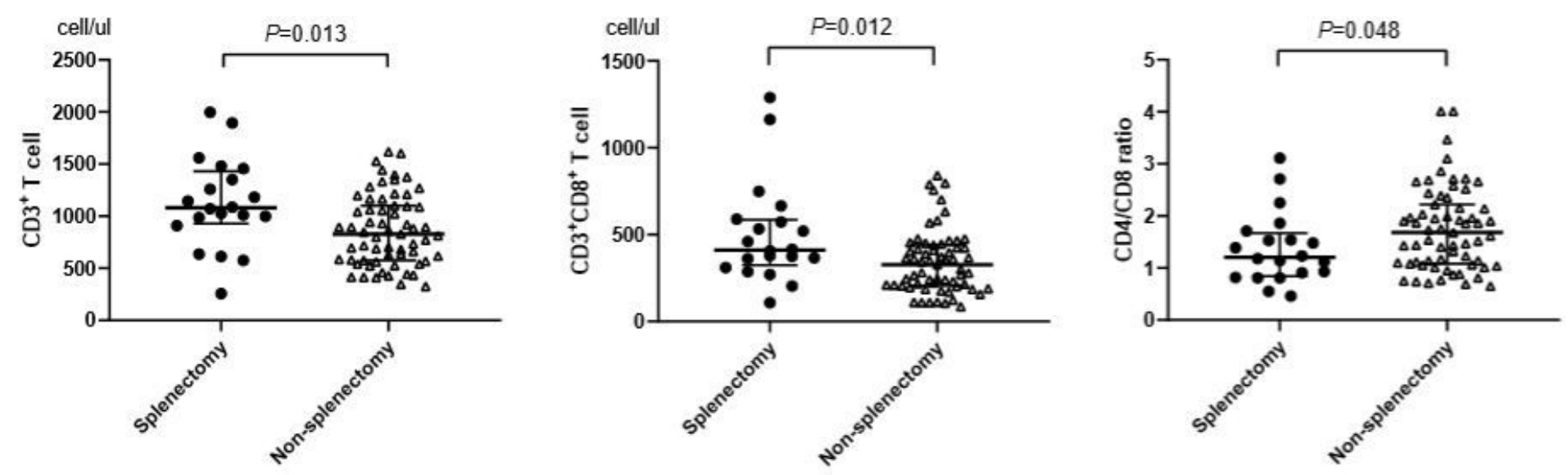

Figure 2

Comparisons with the statistical significance of circulating lymphocyte subsets after surgery (Splenectomy Vs. Non-splenectomy).
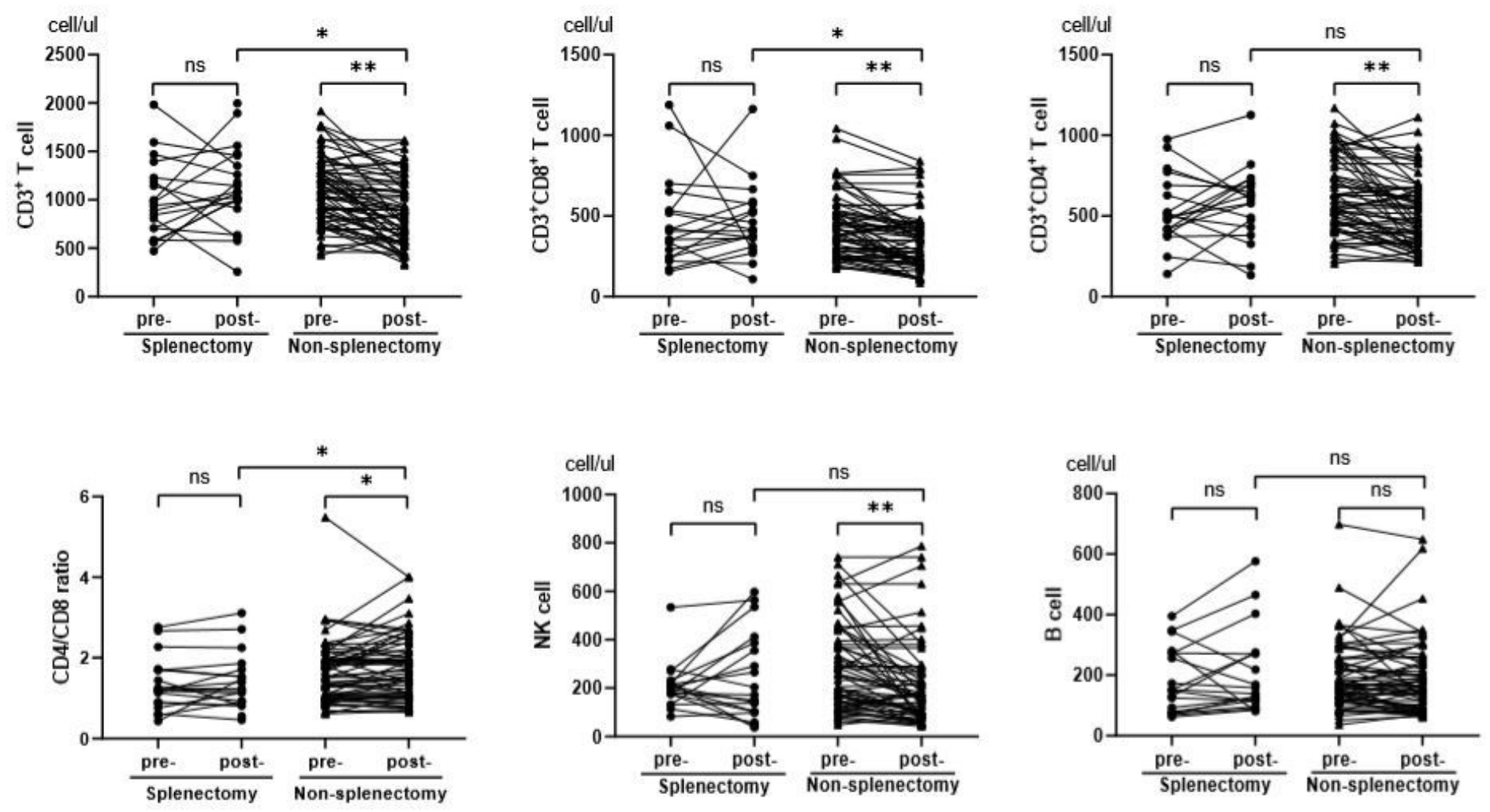

Figure 3

Changes in peripheral lymphocyte absolute numbers in the two cohorts after upfront surgery. Abbreviations: Pre- = before surgery; Post - after surgery. ns=not significant; ${ }^{\star}, \mathrm{P}<0.05 ;{ }^{\star \star} \mathrm{P}<0.01$. 

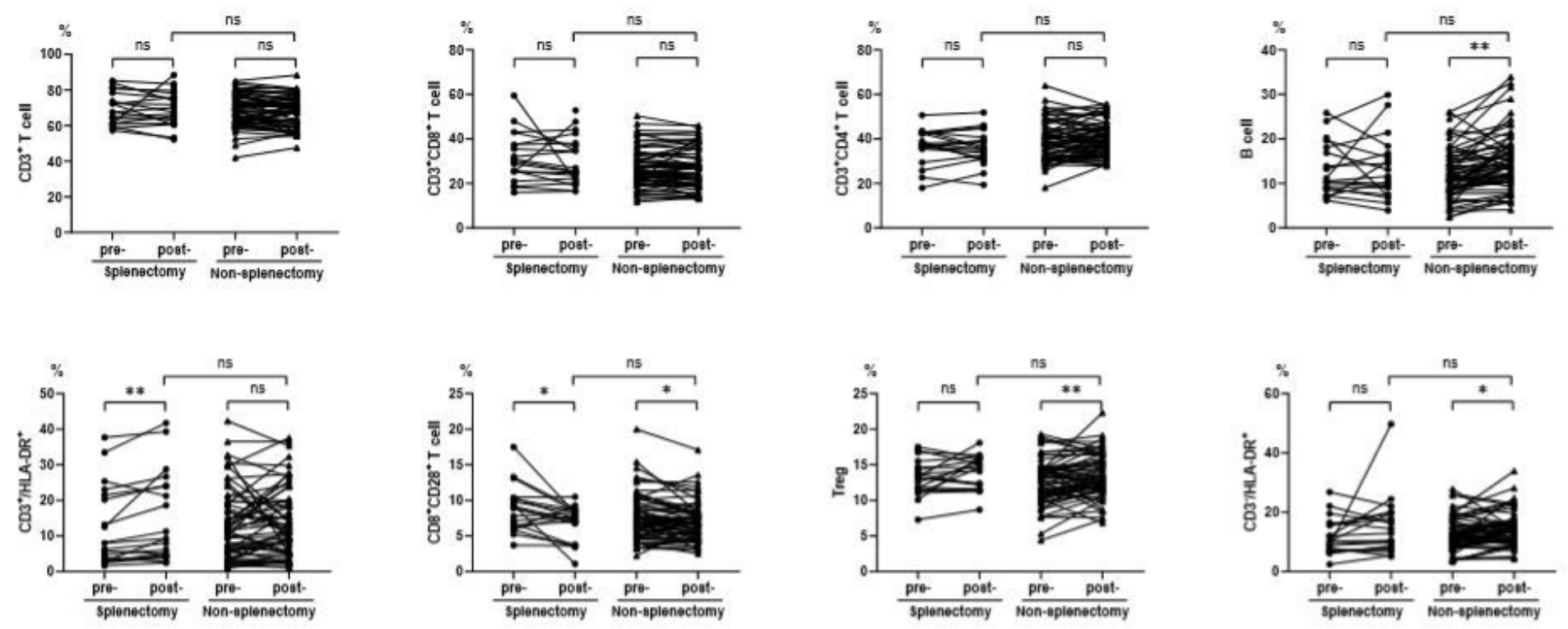

Figure 4

Changes in peripheral lymphocyte distribution in the two cohorts after upfront surgery. Abbreviations: Pre$=$ before surgery; Post- $=$ after surgery. NS=not significant; ${ }^{*}, P<0.05 ; * \star P<0.01$. 